\title{
A força-silêncio do estereótipo: as vozes de Um palimpsesto de putas, de Elvira Vigna
}

\author{
Ricardo Araújo Barberena* \\ Ana Carolina Schmidt Ferrão**
}

\begin{abstract}
O presente texto trata da análise da obra de Elvira Vigna, Como se estivéssemos em palimpsesto de putas (2016), na qual será observada a representação da personagem prostituta. O enredo é conduzido por uma narradora, mas com a inserção de relatos de outra personagem, o João; os dois se encontram num escritório onde ficarão temporariamente. Nesse período, João passa a contar suas experiências sexuais com prostitutas para a narradora, que, ainda que não tenha vivenciado tais histórias, faz suas intervenções, definidas pela própria como "autoria espalhada", e explica: "Eu mesma virando autora. Se não de uma eneida, pelo menos das histórias de putas de um João que nunca termina de fato o que conta, e que vai ficando, ele também, cada vez mais para trás. Os detalhes, aqui, são na maioria meus" (VIGNA, 2016, p. 39). Partindo da afirmação irrefutável de Dalcastagnè (2010, p. 42) de que "Um dos sentidos de 'representar' é, exatamente, falar em nome do outro" chegamos ao que consideramos o âmago da questão da representação literária que envolve a prostituição feminina, posto que "Falar por alguém é sempre um ato político, às vezes legítimo, frequentemente autoritário - e o primeiro adjetivo não exclui necessariamente o segundo".
\end{abstract}

É nesse exato ponto - em que o autor de uma obra, falando por e de um indivíduo outro, valendo-se de sua autoridade - que surge a criação de uma figura estereotipada. Esse romance, por sua vez, nos apresenta um palimpsesto, uma sucessão de estereótipos em relação à prostituição, a maioria enunciados por João, embora a narradora também manifeste alguns, demonstrando como certos estigmas são reproduzidos igualmente por mulheres. No entanto, ao contrário de outras narrativas, a presença dos estereótipos não os reforça, e sim cumpre a função denunciativa, expõe e provoca, realizando o que descreve Brandão:

Professor doutor no Programa de Pós-Graduação em Letras da PUCRS, em Porto Alegre, Rio Grande do Sul, Brasil. E-mail: ricardobarberena@hotmail.com.

* Doutoranda em Teoria da Literatura pela PUCRS, em Porto Alegre, Rio Grande do Sul, Brasil.Email: anacsferrao@gmail.com. 
A mulher representada na literatura, entrando num circuito, produzindo efeitos de literatura, muitas vezes acaba por se tornar um estereótipo que circula como verdade feminina. Presa de representações viris, a mulher pode se alienar nelas, conformando-se em ajustar-se a esses estereótipos, pois a ideologia das representações confunde significante e significado e busca estabelecer uma continuidade do signo com a realidade. Evidentemente, a literatura pode romper com essa ideologia e as utopias que ela produz, revelando-se como artifício, como construção na linguagem, como impossibilidade de uma verdade que preexista ao discurso. É o que acontece com os textos da modernidade que se oferecem como textos, como jogo significante, como desconstrução do próprio sujeito-narrador e como denúncia da ficção, revelando a sua verdade de ficção, tecida com os fios fantasmáticos que se exibem como tais (BRANDÃo, 2006, p. 56).

João, o portador das inúmeras vivências com trabalhadoras sexuais, acredita ultrapassar para um outro universo ao entrar em contato com a prostituição, acredita na ideia "de a garota, nua, ser a entrada para outro mundo, e dele ser a decisão para que mundos aconteçam" (VIGNA, 2016, p. 36), um processo de autoafirmação sustentado por suas experiências com outras mulheres, uma demonstração de poder e superioridade, "João fala e fala. Ele tem temas [...] O terceiro tema é o do poder. Quem, dos envolvidos em uma relação prostituta-cliente, detém o poder" (VIGNA, 2016, p. 61). João está sempre tentando garantir sua supremacia e se relaciona com garotas de programa não em busca de prazer, mas de meios para manter essa soberania, vendo a si mesmo como um ser mais especial que todos: "Ela acaba de se vestir. Diz que os outros caras com quem às vezes sai não a tratam tão bem. Que parecem ter vergonha dela, que não querem ser vistos com ela e que não ficam a noite inteira com ela" (VIGNA, 2016, p. 133). Não há como dissociar a relação de poder que há nessa conjuntura, pois Bhabha (2013, p. 134) elucida que "os sujeitos do discurso são construídos dentro de um aparato de poder que contém, nos dois sentidos da palavra, um "outro" saber - um saber que é retido e fetichista e circula através do discurso colonial como aquela forma limitada de alteridade que denominei "estereótipo". Nesse caso, o estereótipo da prostituta é construído através desse "outro saber", um saber que ignora a realidade do próprio indivíduo:

O estereótipo não é uma simplificação porque é uma falsa representação de uma dada realidade. É uma simplificação porque é uma forma presa, fixa, de representação que, ao negar o jogo da diferença (que a negação através do Outro permite), constitui um problema para a representação do sujeito em significações de relações psíquicas e sociais (BHABHA, 2013, p. 130).

João utiliza os casos com as prostitutas ${ }^{1}$ como ferramenta para se destacar, não apenas de sua companheira, dos amigos e colegas, mas de qualquer pessoa. Por

\footnotetext{
Utilizamos a nomenclatura "trabalhadora sexual" por ser o termo social e político estabelecido pelo grupo de trabalhadoras sexuais; e a nomenclatura "prostituta" por ser o termo mais utilizado nas obras literárias.
} 
isso conta episódios em que as trabalhadoras sexuais o preferem ou o distinguem de outros, afinal, João está acima, pelo menos segundo sua própria narrativa. Nesse trecho, podemos perceber também como o discurso desse personagem assume um tom paternalista, o estereótipo possui tamanha ambivalência que a prostituta pode ser descrita como sagaz e infantil ao mesmo tempo:

A garota abaixou a saia que o cara tinha puxado para cima, isso no meio da boate. Um cafajeste. Ela abaixou devagarinho, olhando para mim com olhar súplice. Não abaixou de todo, como criança que não consegue arrumar direito a própria roupa. Ela estava de fio dental (VIGNA, 2016, p. 98).

João é, de fato, um homem machista, ele inferioriza as mulheres em geral, inclusive a sua própria esposa e a narradora. No que se refere especificamente às garotas de programa, João teve variadas experiências e, ao revelá-las, expõe juntamente o estereótipo no qual enquadrou essas mulheres que não significam nada, um palimpsesto: "João também desenhava. Por cima. E no ar, e com palavras. E nele mesmo. Uma garota de programa por cima de outra garota de programa, sem nunca as individualizar, acabá-las, sempre faltando alguma coisa, calcando mais da próxima vez, quem sabe agora" (VIGNA, 2016, p. 169). E assim como não consegue admitir a capacidade cognitiva de Lola, sua esposa, tampouco dará crédito a qualquer manifestação que venha das prostitutas, "nem passou pela cabeça dele considerar que a garota falava algo importante" (VIGNA, 2016, p. 161). A fixidez do estereótipo não permite que seja abordada a complexidade da subjetividade, muito menos as nuances da identidade, já que, de acordo com Hall (2004), ela está em um processo ininterrupto de reestruturação. Dessa forma, o estereótipo estabelece representações e elas são disseminadas como verdades,

O processo pelo qual o "mascaramento" metafórico é inscrito em uma falta, que deve então ser ocultada, dá ao estereótipo sua fixidez e sua qualidade fantasmática - sempre as mesmas histórias sobre a animalidade do negro, a inescrutabilidade do cule ou a estupidez do irlandês têm de ser contadas (compulsivamente) repetidamente, e são gratificantes e aterrorizantes de modo diferente de cada vez (BнABHA, 2013, p. 134).

O estereótipo da prostituta seguirá a mesma lógica, repetindo "mitos" instituídos, uma figura consagrada pela sua constante reprodução, que se perpetua inclusive pelos próprios integrantes do grupo marginalizado, através do poder da violência simbólica:

A violência simbólica reside nas disposições modeladas pelas estruturas de dominação que as produzem, só se pode chegar a uma ruptura da relação de cumplicidade que as vítimas da dominação simbólica têm com os dominantes com uma transformação radical das condições sociais de 
produção das tendências que levam os dominados a adotar, sobre os dominantes e sobre si mesmos, o próprio ponto de vista dos dominantes (BourdiEU, 2017, p. 64).

O rótulo que recai sobre a prostituta é muito forte, tendo sido construído historicamente, mas não apenas por ser uma figura marginal e estar sob efeito constante da violência simbólica, mas também por fundamentar-se em outro estereótipo igualmente arraigado, o da mulher, que inclui tudo que se refere ao feminino, de forma geral, como elucida Bourdieu:

É, evidentemente, porque a vagina continua sendo constituída como fetiche e tratada como sagrada, segredo e tabu, e porque o comércio do sexo continua a ser estigmatizado, tanto na consciência comum quanto no Direito, os quais literalmente excluem que as mulheres possam escolher dedicar-se à prostituição como a um trabalho (Bourdieu, 2017, p. 32).

Muitas das características estereotipadas que são atribuídas à representação da prostituição pertencem primeiramente à figura da mulher e, obviamente, intensificam-se na prostituta, conforme Bhabha (2013, p. 134): "Como forma de crença dividida e múltipla, o estereótipo requer, para uma significação bem sucedida, uma cadeia contínua e repetitiva de outros estereótipos". Para garantir sua repercussão, fatores diversos são aglomerados ao construir uma imagem fixa, negando assim qualquer particularidade, o que corrobora na constituição de uma figura nula, oca, recheada de vazios.

Ao estereótipo da prostituta, que não pensa e não sente, está intrinsecamente ligado o domínio do corpo, para ser usado como o cliente julgar apropriado, pois, dentro da estigmatização, ele não passa de um objeto. Nesse sentido, em dois eventos João faz valer esse aspecto, usufruindo o corpo da garota de programa como se fosse um brinquedo a sua disposição, colocando alimentos sobre ele, ou até mesmo inserindo-os, despreocupadamente, por diversão; qualquer desconforto que a situação possa causar é observado somente da sua perspectiva, pois João não cessa de ser o protagonista de todas as suas narrativas, "Pus um bombom dentro dela. Chupei. Foi legal. Mas o cheiro de chocolate atrapalhou. Não era para eu sentir cheiro de chocolate nessa hora. Juntou com Todynho, uma coisa de infância. Não sei se a minha, se a do meu filho, mas de qualquer jeito, nada a ver" (VIGNA, 2016, p. 158).

João vê o corpo dessas mulheres como um banquete a sua disposição, posto isso, é imprescindível ressaltar que o corpo do imaginário masculino não é o corpo real, como já mencionado, ele é montado através dessas inscrições de poder e gênero para refletir concepções e expectativas de outros, como bem questiona Calligaris:

Talvez o corpo que reveste as fantasias masculinas sobre a feminilidade não seja um corpo de mulher, mas sim um corpo que podemos pensar 
como um hipotético corpo puramente feminino. Essas fantasias imaginam um corpo que se oferece incondicionalmente. Como se na fantasia masculina o próprio corpo de uma mulher fosse a liberdade em se oferecer ininterruptamente. Se assim fosse, a mulher seria sempre feminina, um eterno vazio, sem significação própria, pronta a se oferecer ao gozo e às fantasias dos outros (CALligARIS, 2005, p. 37).

Nesse contexto, o corpo ocupa um lugar de destaque, quando se trata da mulher, espera-se que seja disponível, frágil e erotizado: "o corpo da mulher, a encarnação do desejo" (FERro, 1997, p. 46); no caso da garota de programa, isso será exaltado, pois ele é o seu meio de trabalho, e deve se tornar um corpo essencialmente submisso e sexual. Afinal, se o objetivo da mulher é servir, o da prostituta o é ainda mais, sob qualquer hipótese, o corpo é o aparelho com o qual ela irá cumprir sua função, "corpo-instrumento, a prostituta representa fundamentalmente para o freguês uma peça de produção do prazer” (RAGO, 2008, p. 259).

Essa curta série - que a narradora nomeia de "barbaridades" - prossegue, depois de "A barbaridade do bombom", João coloca uma pizza fria em cima do corpo da garota, "E faz um segundo round na cama e na pizza, a partir das rodelinhas de tomate, agora acrescidas de mais duas. "Olha só, dois tomatinhos extras!!". Que mordisca" (VIGNA, 2016, p. 159). Torna-se muito evidente o olhar que João coloca sob esses corpos que ele classifica como alimento e objeto, apenas outro pedaço de pizza. Para encerrar a trilogia de barbaridades, João, reafirmando sua superioridade, conta como uma garota "implorou" para trabalhar para ele, "A garota pediu por favor para eu sair com ela, porque se eu não saísse, ela ia ter de acabar aceitando o programa com algum velho gordo qualquer, então ela pedia: por favor. Por favor. E eu saí. E ela teve de pagar o favor" (VIGNA, 2016, p. 159).

A posição de superioridade na qual João se coloca a todo momento é reafirmada em suas palavras de maneira frenética e compulsiva, ele subverte os papéis de prestação de serviço para tentar eximir-se do lugar comum de um cliente qualquer. Como ególatra que é, ele só foca em si, mesmo que isso inclua a exclusão do Outro enquanto indivíduo. O estereótipo implica, automaticamente, a negação da identidade, e, no trecho a seguir, também na negação da existência: "Ela não existia, nenhuma delas existia, garotas de programa não podendo existir realmente, hologramas" (VIGNA, 2016, p. 122). Fica sempre claro que João vê as prostitutas como não-pessoas, ferramentas no seu regime de transgressão:

Garotas de programa não podem ser muito reais para João porque senão não funcionam como garotas de programa. Por um tempo pensei que seriam uma espécie de tela, perfeitas, sem nada que interfira no filme a ser passado. Ninguém nota uma tela, não antes de o filme começar, ou depois que acaba (VIGNA, 2016, p. 59).

Essas mulheres eram como que "imaginadas", servindo o propósito de satisfazer João; elas não eram consideradas “alguém”. Nesse ponto, percebemos nitidamente 
a recusa da subjetividade à prostituta, iniciando por sua forma de identificação mais forte, o nome, "João não guarda o nome de nenhuma das garotas com quem trepou" (VIGNA, 2016, p. 84), delatando a objetificação e a ausência de significado atribuída a elas:

\begin{abstract}
Mas quando ele tentava descrever as garotas, ou quando não tentava e eu pedia, sempre começava da mesma maneira. "Como ela era?". "Uma garota novinha, tesudinha”. Por muito tempo achei que ser novinha era uma fixação mais para a pedofilia da parte dele. Independente se era ou não, acho que também queria dizer que as garotas não tinham marcas. Que não havia nelas marcas de uma vida específica. Eram novinhas no sentido de que não tinham marcas, gestos, expressões, coisas que as individualizassem. De algumas, ele lembrava de alguma coisa, um nariz um pouco maior, um jeito mais sacana de rir inflando as narinas ou franzindo o nariz. Ou era ele que punha, nelas, características, lembranças e ilações que nelas não havia. Da maior parte das garotas, nada ou quase nada ficou para ele (VIGNA, 2016, p. 60).
\end{abstract}

O simbolismo desse ato cruel, o de negar o primeiro vínculo que qualquer sujeito estabelece com sua própria identidade, define a construção da personagem prostituta. Como explica Bhabha (2013, p. 133), "como a fase do espelho, 'a completude' do estereótipo - sua imagem enquanto identidade - está sempre ameaçada pela 'falta'”, por isso a representação da prostituta, sob o viés da estereotipia, é realizada de forma fragmentada, sempre incompleta, pois ignora outras faces da personalidade. João descaracteriza essas mulheres e as deixa nuas de significado. Deste modo, Bhabha (2013, p. 140) declara que "o estereótipo é ao mesmo tempo um substituto e uma sombra", por que assume o local de identificação do sujeito, como verdade sobre ele, mas não se aproxima de nenhum esboço das subjetividades retratadas. Sobre essa relação do estereótipo com a prostituição, Rago (2008, p. 260) escreve que "não interessa nessa relação a pessoa da prostituta, suas ideias, apreensões, desejos, mas uma performance que foi comprada e deve ser satisfeita", confirmando assim a rejeição da individualidade e subjetividade da trabalhadora sexual.

Outros estigmas vão sendo reproduzidos, como uma cadeia contínua, um puxando o outro, como a fixação de João por "novinhas", trazendo o já clássico estereótipo da "ninfetinha", personagem cativa do imaginário masculino. Nesse redemoinho de rótulos, João acaba ficando perplexo quando, lutando contra a maré, a subjetividade o atropela, da mesma forma que se surpreende quando há um rompimento com o perfil que ele espera de uma prostituta:

É a primeira vez que João ganha um presente de uma garota com quem faz um programa. Em vez de dar dinheiro a ela, é ela quem dá algo a ele. Ele se comove de quase chorar quando conta. Depois ele leva a garota para a casa dela e esse lugar ele guarda onde é. Um bairro em cima de uma 
colina da ilha de Manhattam. Um bairro de classe média alta. A garota é uma garota de classe média alta (VIGNA, 2016, p. 134).

Além de expor e questionar os apontamentos de João, a narradora contesta algumas de suas colocações, como no momento em que ele expressa sua concepção sobre a figura da prostituta não confiável, ardilosa e mentirosa, um ponto de vista altamente preconceituoso, considerando sobretudo que a garota de programa estava contando a ele situações pessoais:

\begin{abstract}
A garota diz que vem do Nordeste e que tem um filho que ficou ao encargo de parentes. João acha que é mentira. Não acha. Mas ao me contar, conta fazendo cara de esperto, de homem vivido, de quem sabe que uma história dessas só pode ser mentira. Nada mais lugar-comum do que prostituta que trabalha para manter um filho que ficou no Nordeste. Contam isso para amolecer o coração dos trouxas, diz. Ele sabe disso, e faz um muxoxo. Contam isso para ganhar dinheiro extra. E outro muxoxo. Mais curto: "primeiro, ela faz o programa por menos do que o preço-padrão. Então, não há esperança de ganhar dinheiro extra algum, já que nem o básico ela recebeu". "Tem razão". "Segundo, lugar-comum é apenas uma verdade que se repete" (VIGNA, 2016, p. 57)
\end{abstract}

Em sua pesquisa, Landowski (2012) aponta que existe na sociedade um grupo privilegiado que é responsável por determinar os padrões de interação e vivência. Ele o personificou em uma figura denominada "Sr. Todo Mundo", para conceituar as representações sociais. Nesse sentido, a nossa personagem obviamente não pertence ao grupo dominante e, como os outros marginalizados, acaba por sofrer as imposições do "Sr. Todo Mundo", que "considera como adquirida a irracionalidade (se não a perversidade intrínseca) daqueles que pensam e agem em função de visões do mundo diferentes da sua" (LANDOwski, 2012, p. 6). Sendo assim, João automaticamente estabelece que o relato da trabalhadora sexual é falso, ainda que não haja nenhum indício que leve a esse pensamento, pelo contrário. O universo da prostituta possui outra lógica, outra maneira de ver o mundo, pois ela, por si só, possui outra maneira de existir e sobreviver, dessa forma, torna-se inerente, para a visão hegemônica, a sua devassidão, a sua imoralidade, a sua libertinagem, um ser "maligno" tanto na sua maneira de ser quanto na sua interação com a sociedade.

A prostituição foi focalizada a partir da doença, da degenerescência da raça, da loucura e animalidade das mulheres das "classes perigosas" com a construção de tipos psicofisiológicos - a prostituta, o gigolô, a cafetina - extremamente fixos, determinados pela própria estrutura óssea, base definitivamente imutável do caráter do indivíduo, ao contrário de suas paixões ou fisionomias (RAGO, 2008, p. 192).

O estereótipo da prostituta contamina as percepções sobre ela na sociedade, tornando-a uma pária, um indivíduo a ser extirpado. Então, as prostitutas são configuradas "na construção estereotipada de sua imagem como pura negatividade e 
no engendramento das formas de sua exclusão social" (RAGO, 2008, p. 313), obviamente que no quesito literário o que nos preocupa não é diretamente a sua exclusão social, mas a representação realizada a partir desses estereótipos que alimentam esse ciclo, reforçando tais conceitos. Com muita perspicácia, ainda que muitas vezes João seja entediante e quase intragável, como ela define "João vacilão não presta atenção e nem pensa na vida" (VIGNA, 2016, p. 83), a narradora lança a ele reflexões e o desestabiliza em seus conceitos pré-concebidos, "o tema do poder entre prostituta e cliente é o que menos emplaca, nas nossas conversas no escritório. Minha culpa. Quando o tema ensaiou se estender, cortei: "para mim, vender a buceta ou o bíceps é exatamente a mesma coisa” (VIGNA, 2016, p. 91).

Nem sempre para ele, mas ao leitor, a narradora denuncia as fragilidades e as contradições do discurso de João, "ele, bem firme, discorrendo paternalisticamente sobre a possibilidade do poder de uma prostituta [...] Outra coisa bem diferente é ele se ver igual à prostituta. Ele à venda" (VigNA, 2016, p. 92), como também salienta o equívoco e a cegueira que predominam na percepção de João sobre as mulheres e as prostitutas, ela afirma que Lola "podia ter sido uma companheira. Aliás, ela, as garotas de programa, eu. Igual. Mas para isso, João teria de olhar para o lado. Nunca olhou" (VIGNA, 2016, p. 92).

Não obstante, como já mencionado, em alguns momentos a narradora expressa também concepções estigmatizadas - resultado da eficácia do estereótipo -, como, por exemplo, a questão referente ao futuro da prostituta, a ideia de que ela nunca poderá se desvincular dessa situação de prostituição, uma destruição geral de outras possibilidades de vida:

Ela vai voltar para Petrolina. Vai aceitar o convite do ex-amigo de infância. E aí escuto Mariana dizer isso da mesma maneira que João escuta as histórias em que quer acreditar mas acha que não deve. Imagina se vai dar certo. O ridículo que é acreditar que uma puta com filho pequeno possa voltar para Petrolina com nariz em pé e trabalhar como motorista de alta classe em traslado de aeroporto, eventos, turnês de artistas, excursões turísticas. E que vai dar tudo certo, ela em um dos apartamentos dos edifícios novos que constroem em bairros de classe média, o menino na escola (VIGNA, 2016, p. 107).

Este é mais um aspecto que se relaciona exclusivamente ao campo do trabalho sexual, que perpetua a linha de raciocínio limitadora ligada à prostituta, que insiste em restringir a subjetividade da prostituta em todos os circuitos, é o conceito que sentencia o futuro dessas mulheres à inexistência total, "ocorre na prostituição, uma desistência de futuro, do futuro de si mesma” (Ferro, 1997, p. 99).

Como visto, os estereótipos são fixos e passam a definir os indivíduos através de conceitos deturpados, logo a venda do sexo não é algo que a prostituta faz, um serviço que presta, mas sim algo que ela é, um rótulo irremovível, que ganha o poder de classificá-la, ela passa de sujeito de uma ação ( o serviço que presta) para 
a condição de objeto. Sendo assim, a mulher estará fadada à prostituição, todas as suas escolhas estarão afundadas para sempre, ela jamais terá outro caminho, ainda que queira, não há "recuperação"para este tipo de mulher, já condenada no âmbito social, "mesmo fugindo muito longe durante toda uma vida, nada nos fará esquecer a devastação do que uniu uma puta a seu cliente, nada a fará esquecer essa loucura" (ARCAN apud Figueiredo, 2013, p. 108). Tão arraigada é essa ideia e o preconceito que ela acarreta, que muitas vezes até mesmo a profissional do sexo acaba incorporando o discurso fatalista, o do "caminho sem volta" (FIgueIREdo, 2013, p. 108), isso nada mais é que o resultado da violência simbólica e dos processos de inscrição corporal aos quais estão submetidas.

No entanto, ao contrário de João, a narradora é capaz de refletir criticamente sobre seus conceitos, procurando desprender-se das amarras dos estigmas e não afundar-se mais neles. Sobre o caso específico de Mariana, garota de programa com quem divide o apartamento, ela reconhece o engano:

Um ex-vizinho de infância dela está abrindo uma agência de aluguel de automóveis para atender indústrias que se instalam nos arredores da cidade. Uma nova vinícola. Uma indústria de processamento de massa de goiaba para exportação. A agência atenderia traslados de e para o aeroporto, turismo regional, eventos empresariais e culturais. E o cara diz que quer coisa sofisticada, pessoas com traquejo da cidade grande. Falando um pouco de inglês, até. Na época fico em dúvida se entra prostituição no pacote. Hoje estou convencida de que não. A foto de Mariana de terninho ao lado do carro de luxo é a foto de uma motorista que pode até levar o grupo de gringos para uma boate. Mas não é ela a prostituta. Mariana é uma prostituta com filho pequeno, sozinha no Rio de Janeiro. Trabalha em um puteiro modesto de centro de cidade e acha que vai voltar para o lugar de onde saiu quase adolescente e quase expulsa (pela falta de perspectiva, pela gravidez) e que vai dar tudo certo. Ela fala, concordo sem acreditar nem um pouco. Devia ter acreditado (VIGNA, 2017, p. 75, grifo nosso).

Ao relatar a experiência do grupo de amigos de João com uma garota de programa, a narradora atesta como o tema do estereótipo encontra-se no âmago da questão da prostituição, principalmente para o universo masculino, "faz sentido [...] Não só por ser churrascaria. Carnes à mostra e tal. Mas por ser um clichê de carnes à mostra. Mais um. Esse linguístico mesmo. Porque acho que isso de clichês, banalidades, estereótipos, é a cara que eles têm quando buscam o inesperado, a transgressão" (VIGNA, 2017, p. 83), é o indivíduo limitado em corpo, e esse corpo, por sua vez, limitado em carne. Ainda no mesmo episódio, a narradora expõe outro rótulo, um dos mais fortes e cruéis na construção da figura da prostituta, o de mercadoria, que não admite o trabalho sexual como uma prestação de serviço, mas sim como uma venda de si mesma, perdendo sua autonomia e humanidade.

Na churrascaria, o grupo de homens trata a garota de programa como um objeto meramente decorativo, posto que não está exercendo sua única função, eles 
falam dela como se não estivesse ali e discutem sobre seus seios da mesma forma que se discute os cortes da carne bovina do jantar. O lugar da prostituta é evidenciado: "quem está lá para servir (a garota e o garçom)" (VIGNA, 2017, p. 86). Através de uma negociação que apenas visa o próprio lucro e proveito, marcamna como mercadoria:

Se a garota faz um abatimento porque são três. Pacote promocional. Porque agora se trata de uma transação comercial como outra qualquer e o que vale não é o tostão a mais ou a menos, mas a superioridade intrínseca de quem leva vantagem em uma negociação. Fazem isso enquanto olham para a garota e riem. Ela diz que tudo bem. "Tudo bem" (VIGNA, 2017, p. 87).

Há uma detalhada composição na figura da trabalhadora sexual, incluindo diversos traços, como o estereótipo da imagem da puta, suas vestimentas, seu comportamento, tornando condenável tudo que se associe a esse perfil estabelecido. Através disso se dá a negativização do termo "puta", assim como da própria puta, "a garota ali na rua. Os saltos altos, a saia curta e nem precisa se virar que Cuíca já sabe: o decote" (VIGNA, 2016, p. 83). É preciso que a prostituta se transforme nesse vazio, recheado apenas de estereótipos, um processo torturante de apagamento:

Nada contra a transformação de Mariana em não pessoa. É mesmo divertido ver ela se transformando em a garota perfeita, sem marcas, características próprias ou muito menos defeitos. Ela também acha divertido. Passa base em cima de picada de mosquito. E ri. Eu também rio. O inverso é menos divertido. Quando ela volta e precisa se transformar de não pessoa em pessoa, o processo é doloroso, íntimo. Põe Gael para brincar com alguma coisa. E começa. E é difícil. É difícil para ela limpar a maquiagem em frente ao espelho. O banho também é demorado e difícil. E uma vez que cheguei mais cedo do escritório de João, vi que ela simplesmente sentava no chão do chuveiro e deixava a água escorrer. Por horas. E depois do banho, ela acha que precisa escovar o cabelo por muito, muito tempo. E com gestos bruscos, quase arrancando (VignA, 2016, p. 45).

A narradora cumpre seu papel expondo a complexa corrente de estereótipos, enquanto intensamente problematiza-os. Em contraponto ao estereótipo aplicado na construção das demais personagens prostitutas, a narradora também vai descobrindo traços da personalidade de sua colega de apartamento, como a força, a determinação e a alegria, desvelando, então, a subjetividade de Mariana - estopim do seu processo de desconstrução de estigmas - por intermédio de cenas do cotidiano, um jogo de RPG ou uma faxina:

Aí tem um dia de fim de semana em que chego e ela está de luvas amarelas que vão até quase o cotovelo. Faxina na cozinha. O cabelo na cara e, ao lado, Gael alegre e pelado no chão molhado. Ela está de short e camiseta, 
sendo que a camiseta tem uma mancha, provavelmente de leite com chocolate, de Gael. E ela também está rindo, como Gael. Estupefata de descobrir Mariana como uma pessoa, não tenho outra coisa a dizer. "Tem uma mancha aí na camiseta” (VIGNA, 2016, p. 76).

O fato é que a prostituta está condenada, dentro das representações estereotipadas, a ser sempre uma figura insólita, ou como define Melissa Gira Grant, jornalista americana e feminista: "prostituta imaginária". Constituída, assim, de vários estigmas que atuam em diferentes esferas - vítima, criminosa, indigna, sensual, poderosa, incapaz. Contraditórios e limitados, todos eles possuem uma característica em comum: oprimem e anulam a subjetividade do indivíduo que é a prostituta.

É inegável que todos os caminhos do estereótipo levam a um resultado: a negação da subjetividade. Todos os fatores, objetificação do corpo, transformação em mercadoria, submissão ao controle sexual, desempenham a mesma tarefa, roubam a individualidade e transfiguram uma pessoa em casca oca, o vazio destinado ao feminino e, por extensão, à prostituta. Exatamente por fazer esse jogo de espelhos que revela ora estereótipo, ora subjetividade, que Elvira Vigna consegue conciliar tão habilmente representação e crítica, trazendo-nos os dois ângulos da mesma moeda.

\section{Referências}

BнAвна, Homi K. O local da cultura. Belo Horizonte: Editora UFMG, 2013.

Bourdieu, Pierre. A dominação masculina: a condição feminina e a violência simbólica. Rio de Janeiro: BestBolso, 2017.

BRANDÃo, Ruth Silviano. Mulher ao pé da letra: a personagem feminina na literatura. Belo Horizonte: Editora UFGM, 2006.

Calligaris, Eliana dos Reis. Prostituição: o eterno feminino. São Paulo: Escuta, 2005 .

DALCASTAGnÈ, Regina. Representações restritas: a mulher no romance brasileiro contemporâneo. In: DALCASTAGnè, Regina; LeAL, Virgínia Maria Vasconcelos. (orgs.) Deslocamentos de gênero na narrativa brasileira contemporânea. São Paulo: Editora Horizonte, 2010.

Ferro, Eula Pereira. Prostituição e romance. Goiânia: Ed. UCG, 1997.

FigueIREDo, Eurídice. Mulheres ao espelho: autobiografia, ficção, autoficção. Rio de Janeiro: EdUERJ, 2013.

Hall, Stuart. A identidade cultural na pós-modernidade. Rio de Janeiro: DP\&A, 2004 .

Landowski, Eric. Presenças do outro: ensaios de sociossemiótica. São Paulo: Perspectiva, 2012. 
RAGo, Margareth. Os prazeres da noite: prostituição e códigos da sexualidade feminina em São Paulo. São Paulo: Paz e Terra, 2008.

Vigna, Elvira. Como se estivéssemos em palimpsesto de putas. São Paulo: Companhia das Letras, 2016.

Recebido em 2 de dezembro de 2019.

Aprovado em 2 de março de 2020.

\section{Resumo/Abstract/Resumen}

A força-silêncio do estereótipo: as vozes de Um palimpsesto de putas, de Elvira Vigna

\section{Ricardo Araújo Barberena}

\section{Ana Carolina Schmidt Ferrão}

O presente texto detém-se na análise da obra de Elvira Vigna, Como se estivéssemos em palimpsesto de putas (2016). O processo de construção da personagem prostituta, bem como as características da narrativa que corroboram com o desenvolvimento da identidade, constituem o foco do trabalho. Estarão em pauta variados aspectos que contribuem para uma representação literária pautada no estereótipo; questões essas que envolvem o corpo feminino, a transformação em mercadoria e demais rótulos imputados as trabalhadoras sexuais, esses indivíduos pouco célebres do submundo erótico. A inserção da subjetividade na composição das personagens também será verificada, no intuito de reaver o protagonismo da prostituta - figura estigmatizada tanto na sociedade quanto na literatura - e seu reconhecimento como sujeito. Vigna habilmente apresenta uma série de estigmas para então derrubá-los com os questionamentos de uma aguçada narradora. Por intermédio do seu rol de prostitutas, ou, do seu palimpsesto de putas, ela emprega uma exposição crua e sucessiva de estereótipos, em um modelo denunciativo, que exprime para anular.

Palavras-chave: prostituição, estereótipo, mulher, subjetividade.

The forced silence of the stereotype: The personas of Um palimpsesto de putas, by Elvira Ligna

\section{Ricardo Araújo Barberena}

\section{Ana Carolina Schmidt Ferrão}

This text is an analysis of the novel As if we were in the palimpsest of putas by Elvira Vigna (2016). The process of building the prostitute character, as well as the narrative characteristics that corroborate the development of identity, constitute the 
focus of this essay. There will be several aspects that contribute to a literary representation based on stereotype; these problems involve the female body, commodification and other labels placed on sex workers, those unremarkable individuals of the erotic underworld. The use of subjectivity in the construction of the characters will also be analysed in order to return the protagonism to the prostitute, a figure who is stigmatized both in society and in literature, and to give them recognition as a subject. Vigna skilfully presents a series of stigmas and then breaks them down via the questions of an enthusiastic narrator. Through her list of prostitutes, or her palimpsesto de putas, she employs a crude and successive exposure of stereotypes, in a model of denunciation, which she employs to destroy them.

Keywords: prostitution, stereotype, woman, subjectivity.

La fuerza-silencio del estereotipo: las voces de Um palimpsesto de putas, de Elvira Ligna

\section{Ricardo Araújo Barberena}

\section{Ana Carolina Schmidt Ferrão}

Este texto se centra en el análisis de la obra de Elvira Vigna: Como se estivéssemos em palimpsesto de putas (2016). El proceso de construcción del personaje de la prostituta, así como las características narrativas que corroboran el desarrollo de la identidad, constituyen el foco del trabajo. Serán discutidos diversos aspectos que contribuyen a una representación literaria basada en el estereotipo; cuestiones aquellas que incluyen el cuerpo femenino, la mercantilización y otras etiquetas imputadas a las trabajadoras sexuales, eses individuos poco notables del submundo erótico. Se comprobará también la inserción de la subjetividad en la composición de los personajes, con la intención de recuperar el protagonismo de la prostituta, figura estigmatizada tanto en la sociedad como en la literatura, y su reconocimiento como sujeto. Vigna presenta hábilmente una serie de estigmas y luego los revoca con las preguntas de una entusiasta narradora. A través de su papel de prostitutas, o de su palimpsesto de putas, ella emplea una exposición cruda y sucesiva de estereotipos, en un modelo de denuncia, que se expresa para anular.

Palabras clave: prostitución, estereotipo, mujer, subjetividad. 